\title{
Machine learning for big multimedia analytics
}

Published online: 7 August 2021

๑) Springer Science+Business Media, LLC, part of Springer Nature 2021

Multimedia Tools and Applications gratefully acknowledges the editorial work of the scholars listed below on the special issue entitled "Machine Learning for Big Multimedia Analytics" (SI 1162).

Of 57 papers submitted to this issue, 12 were eventually accepted after a stringent peer review process.

\section{Corresponding Guest Editor}

Jing Tian

National University of Singapore, Singapore

Email: tianjing@nus.edu.sg; isstj@nus.edu.sg

\section{Guest Editor}

\section{Xin Xu}

Wuhan University of Science and Technology, Wuhan, China

Email: xuxin@wust.edu.cn

Publisher's Note Springer Nature remains neutral with regard to jurisdictional claims in published maps and institutional affiliations. 